\title{
Chronic Migraine
}

National Cancer Institute

\section{Source}

National Cancer Institute. Chronic Migraine. NCI Thesaurus. Code C117015.

Episodes of migraine occurring on 15 or more days per month, for more than three months. 